
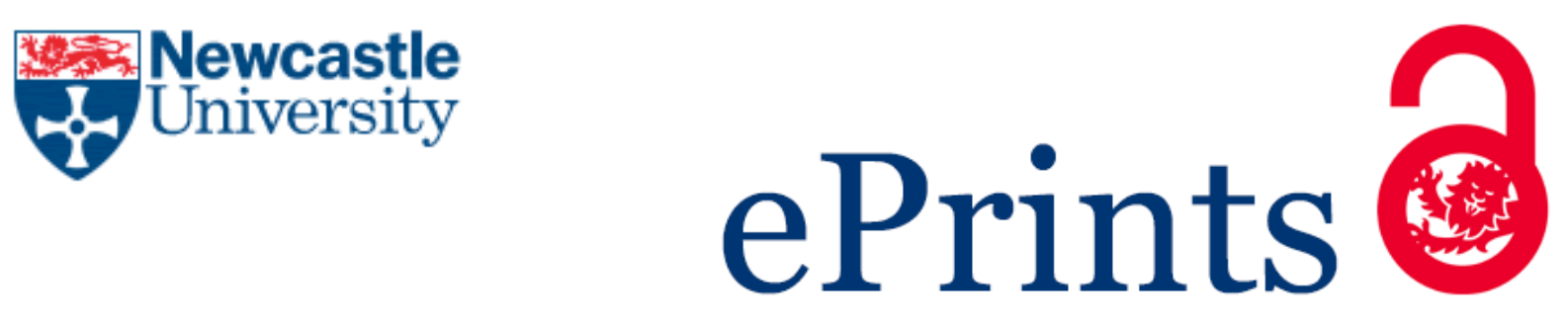

Sneddon LU, Elwood RW, Adamo SA, Leach MC. Defining and assessing animal pain. Animal Behaviour 2014, 97, 201-212.

\title{
Copyright:
}

(C) 2014. This manuscript version is made available under the CC-BY-NC-ND 4.0 license

DOI link to article:

http://dx.doi.org/10.1016/j.anbehav.2014.09.007

Date deposited:

$08 / 02 / 2016$

Embargo release date:

10 October 2015

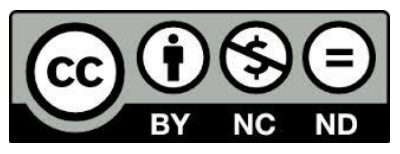

This work is licensed under a

Creative Commons Attribution-NonCommercial-NoDerivatives 4.0 International licence 
1 Defining and assessing animal pain

2

3 Lynne U. Sneddon ${ }^{\mathrm{a}}$, Robert W. Elwood ${ }^{\mathrm{b}}$, Shelley A. Adamo ${ }^{\mathrm{c}}$, Matthew C. Leach ${ }^{\mathrm{d}}$

4

$5 \quad{ }^{a}$ Institute of Integrative Biology, University of Liverpool, UK

6 'School of Biological Sciences, Queen's University Belfast, UK

$7 \quad{ }^{\mathrm{c}}$ Department of Psychology and Neuroscience, Dalhousie University, Canada

$8{ }^{\mathrm{d} S c h o o l}$ of Agriculture, Food \& Rural Development, Newcastle University, UK

9

10

*Correspondence: L.U. Sneddon, Institute of Integrative Biology, University of Liverpool,

The BioScience Building, Liverpool, L69 7ZB, UK. E-mail: Lsneddon@ liverpool.ac.uk

12 (L.U. Sneddon)

13

14

15 
The detection and assessment of pain in animals is crucial to improving their welfare in a variety of contexts where humans are ethically or legally bound to do so. Thus clear standards to judge whether pain is likely to occur in any animal species is vital to inform whether to alleviate pain or to drive the refinement of procedures to reduce invasiveness thereby minimising pain. We define two key concepts that can be used to evaluate the potential for pain in both invertebrate and vertebrate taxa. Firstly, responses to noxious, potentially painful events should affect neurobiology, physiology and behaviour in a different manner to innocuous stimuli and subsequent behaviour should be modified including avoidance learning and protective responses. Secondly, animals should show a change in motivational state after experiencing a painful event such that future behavioural decision making is altered and can be measured as a change in conditioned place preference, self-administration of analgesia, paying a cost to accessing analgesia or avoidance of painful stimuli and reduced performance in concurrent events. The extent to which vertebrate and selected invertebrate groups fulfil these criteria is discussed in light of the empirical evidence and where there are gaps in our knowledge we propose future studies are vital to improve our assessment of pain. This review highlights arguments regarding animal pain and defines criteria that demonstrate, beyond a reasonable doubt, whether animals of a given species experience pain. 

inspiring numerous researchers investigating pain in animals. Bateson set out a clear framework upon which hypothesis driven research questions could be derived regarding the capacity for pain in any species. Indeed the criteria suggested have been applied to numerous species particularly non-mammalian vertebrates (e.g. fish, Sneddon, 2011) and more recently to invertebrates (e.g. crustaceans, Barr et al., 2008). Well-defined criteria were proposed and it was suggested that animals that fulfilled all criteria should be considered capable of pain. These criteria were possession of nociceptors, receptors that detect damaging stimuli on or in the body; pathways from nociceptors to the brain; brain structures analogous to the human cerebral cortex that process pain; opioid receptors and endogenous opioid substances in nociceptive neural system; a reduction in adverse behavioural and physiological effects after administration of analgesics or painkillers; learning to avoid potentially painful stimuli and that this learning is rapid and inelastic; Sneddon (2004) added that normal behaviour should be suspended for a prolonged period rather than a reflex response with adverse changes in behaviour reflective of signs of "discomfort" as shown by long-term motivational change. These robust scientific approaches can provide evidence strongly suggesting that an animal is capable of experiencing pain and we can then seek to reduce or ameliorate that condition by reducing the invasiveness of any procedures to which we subject animals or when this is unavoidable providing pain relief. However, Bateson's review has been recently criticised as being outdated (Rose et al., 2014). Given the advances made in the scientific study of pain, the technologies now at our disposal and more recent evidence from a wider variety of taxonomic groups this review provides a timely update on the definition, assessment and importance of animal pain. 
Nociception, the capacity to respond to potentially damaging stimuli, is a basic

63

64 sensory ability (Purves et al., 2012), and even occurs in bacteria (Berg, 1975). Testing whether animals are able to respond to noxious stimuli is typically straightforward, even though many nociceptors are multifunctional (Tsagareli, 2011). Philosophers and scientists, however, make a distinction between pain and nociception (Allen, 2011) because pain is primarily a subjective experience of anguish, despair and other negative affective states (e.g. see Allan et al., 2005). The difficulty in demonstrating whether animals feel pain, as opposed to just nociception, lies in our ability to recognise negative internal mental states in other species.

Animals have both physiological and behavioural responses to nociception that parallel those that accompany the experience of pain in humans and this is the basis for the argument by analogy (Sherwin, 2001; Allen et al., 2005). However, there are weaknesses to this concept. Clearly animal pain behaviour differs from human pain behaviour, as does the underlying neuroanatomy. When are these differences important (i.e. rendering the argument by analogy invalid) and when are they inconsequential? Understanding the biology of a given species may be helpful here. Some suggest animals may behave as though they are in pain, but this behaviour may reflect nociception without suffering (e.g. Allen, 2004). Thus, analogous behavioural and physiological responses need not imply identical mechanisms. Allen et al., (2005) reviewed the evidence for pain in rodents and compared it with data from humans, concluding that the evidence is not conclusive. However, Shriver (2006) reviewed similar evidence and concluded that it was 'beyond a reasonable doubt' that most mammals feel pain. We review here data that has led to a consensus that it is beyond a reasonable doubt that pain can be experienced in animals (Allen, 2011). This review presents a combination of behavioural, physiological and evolutionary evidence and arguments, which 
taken together demonstrate, beyond a reasonable doubt, that animals from different phyla experience pain.

The opposition to the idea that animals experience pain has sparked fierce debates over the capacity of non-mammalian animals for pain (i.e. non-primates as suggested by e.g. Bermond, 1997, 2001; Rose, 2002; Rose et al., 2014). However, although it cannot be proven that animals experience pain, it also cannot be proven that they do not. We propose that if animals fulfil our criteria below then they should be considered capable, beyond a reasonable doubt, of experiencing pain with implications for their health and welfare.

\section{FUNCTION OF PAIN}

Nociception is a fundamental sensory system that alerts an animal or human to potential damage. Nociceptive pathways connect with brain areas important for motivation, and animals are motivated to avoid the injurious stimulus and protect themselves from further damage (Bateson, 1991). Therefore, it would be adaptive to evolve such a system and many diverse taxa possess specific receptors, i.e. nociceptors that detect damaging stimuli e.g. Drosophila melanogaster and Caenorhabditis elegans (Wittenburg \& Baumeister, 1999; Neely et al., 2010; Im and Galko, 2012). However, different species are likely to show specific differences in how these nociceptors operate.

Evolutionary heritage and life history places very different pressures on animal groups and they are exposed to different types of nociceptive stimuli (e.g. high mechanical pressure, extremes of temperature, noxious chemicals). Therefore, animals will have evolved their nociceptive and possible pain systems to meet the demands of their environment (Broom, 2001; Rutherford, 2002). 

associated aversive motivational state similar to many of the aspects of pain in humans. It is the existence of this aversive motivational state that leads us to propose that, beyond a reasonable doubt, at least some animals experience pain. We should consider the function of this aversive motivational state because it might guide us in establishing how pain might be better defined and shown to be likely in particular taxa. The key function appears to be that the aversive experience of pain creates a strong and lasting motivation that enables the animal to avoid getting into a similar situation in the future. That is it increases fitness by assisting long-term protection from further damage (Bateson, 1991; Sneddon, 2004; Elwood, 2011). Thus, whilst nociception typically allows for an immediate reduction of tissue damage, pain typically allows for longer-term protection. Unfortunately this single criterion, on its own, does not prove that an animal experiences pain. Nociception can also have long-lasting effects without invoking higher-order neural processes (e.g. long-term nociceptive sensitization, Chase, 2002; Smith \& Lewin, 2009). Therefore, such long-term behavioural changes, although consistent with the concept of pain, require further evidence as we discuss below.

\section{DEFINITION OF ANIMAL PAIN}

Because it is impossible to know how a human feels when they are in pain, we rely upon their ability to communicate their experience of pain. This illustrates how difficult it is to measure pain in humans that cannot speak (e.g. neonates) or animals that do not share our language. Therefore, the commonly used definition of human pain cannot be directly applied to animals because it relies on either knowing how an animal feels or requiring them to be 
able to communicate their subjective experiences to us. The International Association for the Study of Pain, defined human pain as "An unpleasant sensory and emotional experience associated with actual or potential tissue damage, or described in terms of such damage" (IASP 1979). However, the IASP (1979) also refers to adults unable to communicate, neonates and infants and adds that "The inability to communicate verbally does not negate the possibility that an individual is experiencing pain" and so we believe this can be applied to animals.

It is vital that an animal-based definition of pain allows rigorous scientific investigation of disparate species and also allows us to detect, assess and alleviate pain in animals where possible. The most commonly used definition for animals is "an aversive sensory experience caused by actual or potential injury that elicits protective and vegetative reactions, results in learned behaviour, and may modify species specific behaviour" (Zimmerman, 1986). Sneddon (2009) refines this definition suggesting that animals in pain should 'quickly learn to avoid the noxious stimulus and demonstrate sustained changes in behaviour that have a protective function to reduce further injury and pain, prevent the injury from recurring, and promote healing and recovery.' We use these definitions as the foundation for our criteria by which possible pain experience might be judged.

Pain provides strong motivation for animals to learn to avoid damaging stimuli in a few trials (Carlsson et al., 2006). The aversive experience associated with pain is probably an important driver in ensuring that animals survive in a dangerous habitat avoiding injury that may otherwise lead to ill health and mortality. Instead of considering pain to be a special property of humans, it is likely that pain and its associated motivational state has an adaptive survival function for animals. We believe that the aversive affective component of pain, therefore, is integral to its evolutionary function (Dawkins, 1980; Stamp Dawkins, 2012) otherwise animals would frequently damage themselves in the same manner and be incapable 
of altering their behavioural decisions to learn to avoid injury. A negative internal state can produce robust and repeatable changes in behaviour induced by damaging stimuli in animals. However, other mechanisms might also produce some similar effects (e.g. nociceptor sensitization, Smith \& Lewin, 2009). Further, animal pain may not be identical to the internal subjective experience that humans have but it does have the same protective function (Rutherford, 2002).

Clever experimentation can yield insights into the animal's experience (e.g. selfadministration of analgesia, Danbury et al., 1997; selective attention, Sneddon et al., 2003a; Ashley et al., 2009; paying a cost to accessing analgesia). Examples of potentially painful events leading to motivational changes suggest the potential for a negative affective state associated with injury. Here we list criteria that animals can be tested against to determine their potential capacity for pain. Determining whether a specific species experiences pain will typically require species-specific behavioural and physiological tests. These are based upon the mechanisms to detect, react and respond to pain and have two key sets of evidence (Table 1): 1. Whole animal responses to noxious stimuli such as physiological change and effects of analgesics and local anaesthetics which differ from those to innocuous stimuli and 2 . Evidence of long-term motivational change that might include rapid learning. These criteria must be considered as a whole and not as indicators in isolation (Table 1). For many species specific data are lacking and for the future of the field it is imperative scientists continue to test the evidence for pain experience in animals (Table 2). Further, we accept that the distinction between these two sets may mean responses can be considered to belong to both criteria. Before we review this evidence, however, we examine another criterion suggested by Bateson (1991), i.e. that an animal requires the neural apparatus to detect, possess and respond to tissue damage for it to feel pain. That is the animal must have an effective 
nociceptor system to enable a neural input allowing perception of tissue damage. However, having that system does not mean that pain will follow.

\section{THE NEURAL APPARATUS}

Nociceptors (A and C fibres) are found in most groups of vertebrates, including mammals (Carstens \& Moberg, 2000, Weary et al., 2006), birds (Breward \& Gentle, 1995; Gentle \& Tilston, 2000; Gentle et al., 2001; 2003; McKeegan et al., 2002; McKeegan, 2004; Hothersall et al., 2011), reptiles (Liang \& Terashima, 1993; Terashima \& Liang, 1994), amphibians (review in Guenette et al., 2013) and fish (e.g. Sneddon, 2002; Roques et al., 2010). However, the proportion of $\mathrm{A}$ and $\mathrm{C}$ fibres may differ between groups. In mammals these fibres link to CNS structures and pathways (at least at the subcortical level) (Carstens \& Moberg, 2000, Weary et al., 2006,), and so are capable for the sensory (i.e. nociceptive) component of pain. For example, Hess et al. (2007) demonstrated that nociceptive activation with inflamed paw in rats, Rattus norvegicus, induced activation of the primary somatosensory areas (areas in humans associated with affective experience); insula, anterior cingulate cortex and medial thalamus using fMRI. Avian nociceptive afferents also project to the brainstem and ascend to the primary presumed pain centres in the forebrain (Dubbeldam, 2009). A key difference between mammals and birds, however, is a substantial divergence in the sequence of the vanilloid receptor 1 (VR1) that binds capsaicin ( $68 \%$; Jordt \& Julius, 2002). Whilst mammals find the burning sensation noxious and avoid eating chili peppers capsaicin does not activate the avian receptor so birds can ingest these and act as an aid to dispersal of the seeds. This is a convincing example of how evolution shapes nociceptors. 
In amphibians the ascending tracts reach the brainstem and the thalamus and project to the cortex (Vesselkin et al., 1971; Kicliter \& Ebbeson, 1976). Within the teleost brain there are various connections to the thalamus and cortical areas (Rink \& Wulliman, 2004). Furthermore, forebrain and midbrain areas are active during potentially painful stimulation and this differs from innocuous treatment (e.g. gene expression in common carp, Cyprinus carpio, and rainbow trout, Oncorhynchus mykiss, Reilly et al., 2008b; electrical activity in Atlantic salmon, Salmo salar, Nordgreen et al., 2007; goldfish, Carassius auratus, and rainbow trout, Dunlop \& Laming, 2005; activity using functional magnetic resonance imaging (fMRI) in common carp, Sneddon, 2013) thus activity is not restricted to merely hindbrain and spinal cord nociceptive reflex centres (Rose, 2002). Further, nociceptors in teleost fish are strikingly similar to mammalian nociceptors (Sneddon, 2003a; 2004; 2011; 2013 Ashley et al., 2006; 2007; Mettam et al., 2012). However, rainbow trout nociceptors are not responsive to cold temperatures below $4^{\circ} \mathrm{C}$ (Ashley et al., 2007). This is intuitive since these fish may frequently encounter such low temperatures and it would not be adaptive to et al., 1993; Kitchener et al., 2010). However, electrophysiological studies are needed to determine whether nociceptors occur in this group.

These studies demonstrate that most vertebrates not only have nociceptors but also that they link to the brain so they at least have the capacity for some sort of "central experience" of the noxious stimulus and this is essential for pain to be considered as a possibility. The situation in arthropods and molluscs, however, is not so clear cut. Certainly, as previously noted, they have nociceptors that allow for perceptual input (reviewed by Elwood, 2011; Crook et al., 2011; Dyuizen et al., 2012). Indeed, much is known about the functioning of nociceptors from the elegant work employing specific mutants with specific 
nociceptor variants (Tobin \& Bargmann, 2004) but our knowledge of the brains of these

232

233

234

235 animals is not so established as that for vertebrates. Nevertheless, long-term changes in central nervous activity have been noted in shore crabs, Hemigrapsus sanguineus, following a noxious stimulus (Dyuizen et al., 2012) and thus information from nociceptors must be conveyed to central areas. Further, there are sustained increases in nociceptor firing following tissue damage in cephalopods, coupled with long term alteration of motivational state (Crook et al., 2013). Thus there is the potential for central processing of information about noxious stimuli in some invertebrates. Here we examine evidence that might indicate that at least some animals fulfil our criteria for pain, starting with the five main groups within the Phylum Chordata, then the Mollusca and finally the Arthropoda.

\section{MAMMALS}

\section{Whole animal response}

Stimuli that are considered painful in humans have been shown to induce similar physiological and behavioural changes in other non-human mammals. The majority of physiological changes associated with potentially painful stimuli are mediated by the sympathetic nervous system and hypothalamic-pituitary-adrenal axis (HPA). The sympathetic responses can be determined either directly by measuring the circulating catecholamines, adrenaline and nor-adrenaline (e.g. Raekallio et al., 1997, Mellor et al., 2002), or the resulting autonomic changes such as heart rate (e.g. Peers et al., 2002, Arras et al., 2007), blood pressure (Peers et al., 2002, Keating et al., 2012), body temperature (e.g. Hellebrekers et al., 
1994), respiratory rate (e.g. Hellebrekers et al., 1994), and body weight change (e.g. Liles et al., 1998). HPA changes in response to painful stimuli are most commonly assessed by measuring production of glucocorticoids such as in rodents (e.g. R. norvegicus, Goldkuhl et al., 2010, Kalliokoski et al., 2010), horses, Equus ferus caballus, (e.g. Pritchett et al., 2003), sheep, Ovis aries, (e.g. Kent et al., 1993), and cattle, Bos primigenius, (e.g. Robertson et al., 1994). These physiological changes are universally considered to reflect negative states that are inevitably associated with pain, for example, fear (Sapolsky et al., 2000).

Behaviour represents the most commonly used index of animal pain and can be categorised by its level of complexity. At the simplest level it is a single reflex response to noxious stimuli (nociception) that does not require higher processing (i.e. experience). However, as the complexity of a behavioural response increases the likelihood of it requiring higher processing also increases. Painful stimuli cause changes in general behaviour, painspecific behaviours and facial expressions that occur beyond acute application of the noxious stimulus. However, these responses have been argued to represent 'complex' reflex responses (e.g. Rose et al., 2014), and they can be mimicked by robots (e.g. Lee-Johnson \& Carnegie, 2010; Breazeal, 2011). However, when potentially painful stimuli alter decisions and choices made by the animal (e.g. preference for pain relief, reaction to other non-pain related stimuli etc.) then they are demonstrating a level of behavioural complexity that is likely to require some negative internal experience (i.e. pain).

Measuring both changes in general behaviour and the development of abnormal behaviour are often used to assess pain, including demeanour (e.g. Stanway et al., 1996), reaction to handling (e.g. Thornton \& Waterman-Pearson, 1999), posture (e.g. Slingsby \& Waterman-Pearson, 1998), activity (Roughan \& Flecknell, 2000), vocalisation (e.g. Hellebrekers et al., 1994), food and water intake (e.g. Leach et al., 2009), gait (Sprecher et al., 1997), rearing (Matson et al., 2007) etc. As Weary et al., (2006) propose often the most 
effective behavioural indicators of pain are those that animals are highly motivated to perform, for example, rodents are highly motivated to rear up in their cages, but this significantly declines after abdominal surgery (Roughan \& Flecknell, 2001). Reviews by Carsten \& Moberg (2000), Rutherford (2002) and Weary et al. (2006) provide a comprehensive overview of behavioural-based indicators and their validation in mammals. As a consequence, pain-specific behavioural indices have been identified and constructed into assessment schemes in a range of species, including rodents (e.g. Roughan \& Flecknell, 2001, 2003, Wright-Williams et al., 2007) rabbits, Lepus curpaeums, (e.g. Leach et al., 2009), lambs, O. aries, (e.g. Molony \& Kent, 1997), cattle (Molony et al., 1995, Faulkner and Weary, 2000), pigs, Sus scrofa domesticus, (Taylor \& Weary, 2003, Leslie et al., 2010), and horses (Ashley et al., 2005).

Facial expressions are routinely used to assess pain in humans, particularly in those who are unable to communicate (Williams, 2002) and considered to offer an effective method using a limited range of indicators that are a rapid and easy measure with minimal training. Facial expressions are scored using a Facial Action Coding Scheme (FACS) that measures the individual movements or 'action units' of the face that comprise an expression (e.g. Ekman \& Friesman, 1978). Recently similar schemes ('Grimace Scales') have been developed for a limited number of mammalian species including rodents (Mus musculus, Langford et al., 2010, Leach et al., 2012, R. norvegicus, Sotocinal et al., 2011,), rabbits (Keating et al., 2012), and horses (e.g. Dalla Costa et al., 2014). Each grimace scale comprises a number of anatomically based 'action units' (e.g. changes in the shape of the eyes, nose, cheeks, mouth and ears).

The exhibition of both behavioural and facial indicators have been shown to change from before to after a painful event, and these changes can be reduced by the administration of routinely used pain-relieving drugs or simply by time (i.e. recovery). Although many 
authors believe that such complex responses that are observed alongside other potential indices of pain demonstrate higher processing (i.e. experience), we currently have limited objective evidence that the behaviour reflects an integrated response to external stimuli and relates directly to an affective state. However, a study by Langford et al. (2010) may provide such evidence. In this study, mice, M. musculus, underwent lesioning of the rostral anterior insula (implicated in the affective component of pain in humans) and this prevented changes in facial expression but not abdominal writhing (the behavioural marker of abdominal pain or nociception). A similar effect is observed in humans with insular lesions that are associated with pain asymbolia (the disassociation of the affective [unpleasant experience] and the sensory component [nociceptive response] of pain) (Langford et al., 2010). In these patients the emotional responses to pain significantly decline without the associated reduction in nociceptive response or pain thresholds (Berthier et al., 1987).

\section{Long-term motivational and behavioural change}

Amongst some of the most complex behavioural responses to pain are those in preference and avoidance studies. These demonstrate that animals are able to use their internal 'state' (i.e. apparent experience of pain to learn, make decisions and then perform behaviours that ameliorate that pain state). For example mammals show avoidance of places in which potentially painful stimuli are delivered (Gao et al., 2004) and will pay a cost to avoid such stimuli. Rats will cover electrodes in their cages with bedding so shock can be avoided (Pinel et al., 1989). Further, there are numerous examples of long-term directed licking or rubbing of the body area damaged by a noxious stimulus (e.g. Wheeler-Aceto \& Gowan, 1991). Mammals also show "pain relief learning" in which stimuli that are temporally associated with the termination of a noxious stimulus e.g. electric shock, have a positive valence and are 
preferred over neutral stimuli (Gerber et al., 2014). Such responses are much more difficult

to account for as being simply a complex reflex or nociceptive sensitization as they require considerably higher processing (Bateson, 1991). Further behavioural tests commonly assess how animals respond when given a choice to avoid a situation that is associated with pain or choose a drug that relieves pain. For example, Colpaert et al. (1980) demonstrated that rats given a choice between sugar solution and solution containing pain-relief chose the sugar solution if healthy (non-painful), but the pain-relief containing solution when experiencing a potentially painful condition (arthritis). These studies on mammals provide the benchmark upon which other animals are judged by, and certainly provide a basis for testing species where pain has not been explored.

In the future, 'cognitive bias' testing may offer a more direct means of assessing the affective component of pain in mammals. This technique has only been applied to animals relatively recently and involves measuring cognitive or judgement biases in the interpretation of ambiguous information (e.g. Harding et al. 2004, Mendl et al. 2009, Brydges et al. 2010, Douglas et al. 2010). To date this technique has focused on the impact of environmental and husbandry procedures on affective state, however, such measures could be directly applicable to the assessment of affective component of pain. It could be argued that such measures would offer the most valid indicators of pain as they could determine the significance of the pain to the animals. Therefore the potential merits of these techniques warrant their inclusion in this review, even though they have not been used in this context.

\section{BIRDS}


(review in Prunier et al., 2010) e.g. plasma corticosterone and heart rate increase after beak

Davis et al., 2004). Birds also exhibit withdrawal responses to a variety of noxious treatments that are used as standard in mammalian pain studies. For example, foot withdrawal in response to high temperature in parrots, Amazona ventralis, kestrels, Falco sparverius, and chickens, Gallus gallus domesticus (Roach \& Sufka, 2003; Hothersall et al., 2011; Geelen et hot water in Japanese quail, Coturnix japonica (Evrard \& Balthazart, 2002) as well as movement away from mechanical stimuli (Evrard \& Balthazart, 2002; Hothersall et al., 2011). Application of analgesics increased the thermal threshold for foot withdrawal in kestrels and parrots (Geelen et al., 2013; Guzman et al., 2013). Morphine significantly reduced responsiveness to noxious heat and mechanical pressure in quail (Evrard \& Balthazart, 2002) and the NSAID dexamethasone significantly diminished the inflammation and hyperalgesia to carrageenan in chickens (Roach \& Sufka, 2003). Further, some analgesic drugs are administered to ameliorate apparent pain, suggesting a high evolutionary conservation of receptors for drugs such as opioids and NSAIDs (Jordt \& Julius, 2002; Nasr et al., 2012).

\section{Long-term motivational and behavioural change}

Self-selection of analgesic dosed food has been demonstrated in chickens where lame birds selectively choose food drugged with carprofen (Danbury et al., 2000). This approach has had mixed results in other pain models where beak trimmed birds did consume more 
carprofen dosed food but this did not return pecking rates to normal yet the maximum force exerted while pecking was higher than groups not receiving carprofen (Freire et al., 2008). Putting chickens in a novel situation or starving them to elicit a motivational shift to feed reduces pain-related responses (Wiley \& Gentle, 1998; Gentle \& Tilston, 1999). This may mean that pain is not as important as satiating hunger or exploring a new habitat. However, this shows that the reactions to pain are not simple reflexes otherwise the birds would perform the same behaviour regardless of context. The behaviours seen after a painful event are indicative of abnormal behaviours and certainly guarding behaviour where an animal does not use a painful area or limb. Birds with keel fractures substantially reduce their movement to new perches as well as taking longer to reach a food reward in runway tests (Nasr et al., 2012). Flight from perch to the ground may require more complex motivational decisions as well as integration of movement and decision making that is impaired by keel fractures but administration of butorphanol substantially increased mobility (Nasr et al., 2012). Thus, behavioural decisions are demonstrably affected by pain in birds.

As with mammals, cognitive bias testing may also offer a more direct means of assessing the affective component of pain in birds. To date, this technique has focused mainly on the impact of environmental conditions on affective state by measuring cognitive biases in the interpretation of ambiguous information (e.g. Matheson et al. 2008, Brilot et al. 2010). Like mammals, this technique has considerable potential utility for the assessment of pain in birds (see the mammal section for more detail).

\section{AMPHIBIANS AND REPTILES}

\section{Whole animal response}


Amphibians show a classic wiping response to application of acetic acid as well as a

404 withdrawal response to noxious heat and mechanical stimulation (Willenbring \& Stevens, 1995) that are attenuated by administration of compounds with analgesic properties (Kanetoh characteristic responses to painful stimulation (e.g. limb retraction in response to formalin in Speke's hinged tortoise, Kinixy's spekii Wambugu et al., 2010; withdrawal from high temperatures in bearded dragons Pogona vitticeps, and corn snakes, Elaphe guttata, Sladky et al., 2008 and in turtles, Trachemys scripta, Sladky et al., 2007; withdrawal from a strong mechanical pressure in red eared slider turtles, Trachemys scripta elegans Kischinovsky et al., 2013) that are again reduced by analgesia. delta, and kappa opioid receptors but also the opioid receptor-like protein (ORL) (Stevens et al., 2009). Sequence comparisons have demonstrated that the amphibian opioid receptors are highly conserved (70-84\% similar to mammals) and are expressed in the CNS areas apparently involved in pain experience (Stevens, 2004; Stevens et al., 2007). Therefore, as one of the criteria for pain that Bateson (1991) suggested, amphibians and reptiles share a similar opioid and endogenous opioid system involved in pain mechanisms with mammals.

\section{Long-term motivational and behavioural change} required to fully understand the implications of potentially painful events on their biology, 
behaviour and welfare (Table 2; Mosley, 2006; 2011). Given the lack of empirical evidence

Mosley (2011) suggests clear criteria when assessing pain in reptiles that could be applied to amphibians. Parameters such as, gait, unwillingness to perform normal behaviours, exaggerated flight response, closure of eyes, decreased appetite, colour change, and abnormal respiration may act as key indicators to assessing affective state (Mosley, 2011). Caution should also be applied in light of life history and ecological differences since some reptile species live in deserts where they would regularly experience extreme heat that would be nociceptive to mammals and as such when applying hot or cold noxious temperatures it may be important to understand whether cooling or warming the test species is a more relevant pain test (Mosley, 2006). For example, red eared slider turtles acclimated to $20^{\circ} \mathrm{C}$ lost nociceptive sensation compared with those held at $35^{\circ} \mathrm{C}$ who were fully responsive to mechanical pinching (Kischinovsky et al., 2013). Thus, an intelligent understanding of what the species will experience should be used to inform meaningful experimental studies.

\section{FISH}

\section{Whole animal response}

Teleost fish move away from noxious stimuli that would cause pain in mammals. For example, koi carp, C. carpio, move away from a clamp exerting high mechanical pressure to the lip and tail and that this response is decreased when the fish are anaesthetised (Stockman et al., 2013). Classical conditioning studies using the negative reinforcement of electric shock is a popular paradigm in fish experiments (e.g. Yoshida \& Hirano, 2010). Rainbow trout and goldfish learn to avoid an area where electric shock is given (Dunlop et al., 2006) but trade off the risk of entering the shock zone when they are fed there to satiate their hunger after 

demonstrated that responses to electric shock were reduced by the opioid painkiller, morphine, and that in turn the effect of morphine was blocked by the antagonists MIF-1 and naloxone.

In vivo administration of potentially painful stimuli results in prolonged, complicated responses (reviews in Sneddon, 2009). Physiologically, opercular beat rate (ventilation of the gills) is enhanced by subcutaneous injection of noxious chemicals in trout, O. mykiss, and zebrafish, Danio rerio, as well as an increase in plasma cortisol in trout (Sneddon, 2003b; Reilly et al., 2008a; Ashley et al., 2009). Concomitantly trout and zebrafish exhibit a reduction in swimming activity (Sneddon, 2003b; Reilly et al., 2008a; Correia et al., 2011). When injected with noxious chemicals into the frontal lips, trout suspend feeding behaviour for 3 hours and only resume feeding when their behaviour and physiology returns to normal (Sneddon, 2003b); sham handled and saline injected controls resume feeding after 80 minutes as do acid injected fish when administered with morphine. Thus this suspension in feeding is similar to guarding behaviour where mammals and birds do not use an affected area or limb to prevent further pain and injury to the site. Fish are the most diverse vertebrate groups and there are obvious species differences in pain related behaviour in mammals (Flecknell et al., 2007) and studies have demonstrated this between fish species. Piaçu, Leporinus macrocephalus, injected with formalin and Nile tilapia, Oreochromis niloticus, that have had the tail fin severed actually increase swimming after the painful treatment (Roques et al., 470 2010; Alves et al., 2013). In contrast, Atlantic salmon experiencing abdominal peritonitis due to vaccination decreased swimming and suspended feeding for up to two days (Bjorge et al., 2011). Therefore, these disparate responses highlight that pain indicators will have to be quantified on a species by species basis and to different modes of pain in fish. Adverse 
changes in behaviour last from three hours up to two days and are not simple instantaneous nociceptive reflexes.

\section{Long-term motivational and behavioural change}

Anomalous behaviours such as tail beating in zebrafish with acid injected near the tail

fin (Maximino, 2011); rocking to and fro on the substrate by rainbow trout and common carp injected with noxious chemicals and rubbing of the injection site by rainbow trout and goldfish (Sneddon, 2003b; Sneddon et al., 2003b; Reilly et al., 2008a; Newby et al., 2009), are only seen in fish given a potentially painful treatment and not observed in sham handled controls, saline injected fish or reported in any other toxicological studies using fish. Therefore, these are likely to be specific to pain and are ameliorated when painkillers are given and may be valid indicators of discomfort and suffering (Sneddon, 2003b; Mettam et al., 2011).

As described above fish are able to learn to avoid noxious stimuli and the experience affects subsequent behaviour. For example, goldfish and rainbow trout avoid an area where they received an electric shock (Dunlop et al., 2006). As many studies demonstrate fish do not feed when in pain, it is difficult to attempt the type of self-administration approaches that have been used in birds and mammals where food or water is dosed with a painkiller (e.g. Pham et al., 2010). However, understanding how important the experience is to fish can be tackled by determining if fish will pay a cost to accessing analgesia. Zebrafish given access to a barren, brightly lit chamber or an enriched chamber repeatedly choose the enriched area. When these fish are subcutaneously injected with acetic acid or saline as a control they still choose the same favourable, enriched chamber. However, if an analgesic is dissolved in the barren, un-preferred chamber zebrafish injected with noxious acid lose their preference for 
the favourable area and spend over half their time in the unfavourable, barren chamber (Sneddon, 2013). This suggests they are willing to pay a cost to enter a less preferred environment to access pain relief.

Selective attention approaches have been employed to understand the importance of the pain experience to fish. For example, trout will ignore novel objects in fear tests rather than show neophobia when in apparent pain, however, this is reversed when morphine is administered (Sneddon et al., 2003b). Noxiously stimulated trout also do not show appropriate anti-predator responses by seeking cover and performing escape behaviour (Ashley et al., 2009). Therefore, in the context of fear and predation pain is the imperative. Piaçu exposed to a predator stimulus show an enhanced stress response and endogenous analgesia where endorphins reduce the impact of painful treatment (Alves et al., 2013). These studies combined demonstrate that painful stimuli appear to take priority over competing stimuli and that central mechanisms are activated to reduce pain.

\section{MOLLUSCS}

(1)

Molluscs include bivalves, gastropods, nudibranchs and cephalopods, which differ markedly in morphology, behaviour and neural complexity (Crook \& Walters, 2011). Various species respond to noxious stimuli and show associative learning (Kavaliers, 1988; Crook \& Walters, 2011). Cephalopods are highly mobile with a large, complex brain and good learning ability (Mather 2011) and they have recently been included in the European Union Directive (2010/63/EU) that provides protection from suffering in animal experimentation. The responses of squid (Loligo pealeii) to localised injury are difficult to explain without invoking long term changes within central processing centres in the brain (Crook et al., 

more than ten minutes after injury. Increased defensive responses to visual stimuli would typically have been interpreted as indicating increased fearfulness in mammals. It certainly demonstrates a long-term change in motivational state after injury, which is consistent with the concept of pain. Additionally, injured animals show increased sensitivity after injury. Squid with a small area of a fin crushed with forceps showed more firing of nociceptors when that area was subsequently touched. This enhanced sensitivity had a rapid onset and lasted for approximately 70 minutes (Crook et al., 2013). However, squid do not appear to show targeted wound-tending behaviour (Crook et al., 2011), although increased sensitivity and prolonged behaviour directed at the site of a wound has also been observed in the octopus Abdopus aculeatus (Alusay et al., 2014). Long-term sensitization of nociceptors (Crook et al., 2013) and defence responses (Crook et al., 2011) have been interpreted as indicating ongoing pain in vertebrates, but possibly do not require complex neural processing (Chase, 2002). The function of the sensitization was tested by Crook et al. (2014) by injuring squid, some with and some without anaesthetic, and comparing to uninjured controls, again some with and some without anaesthetic. The squid were then exposed to predatory fish which showed increased attention to the injured animals regardless of anaesthetic treatment. However, injured squid initiated defensive responses earlier than did controls but this effect was blocked by the anaesthetic. The anaesthetic also blocked the sensitization that normally follows injury and these squid had a lower survival from predatory attempts than did those not given anaesthetic. However, anaesthetic without injury did not reduce survival indicating that there was a positive fitness effect from the sensitization. These data are important as they are consistent with the idea that pain-like states function to promote future survival. hermit crab prey, Pagurus pollicaris, had stinging anemones, Calliactis tricolor, on their 
shells are also consistent with the idea of responses not explained by nociception (review in

549 Elwood, 2011). These long-term behavioural and neuronal changes should be viewed in the context of the advanced learning ability of cephalopods (Mather, 2011).

551

552

\section{ARTHROPODS - DECAPODS}

553

554

Various decapod crustaceans have been investigated to determine if responses to noxious stimuli are merely nociceptive reflexes, with no short-term or long-term effects on CNS function. Shore crabs (C. maenas) show rapid (two trial) discrimination avoidance learning when shocked in one of two dark shelters (Magee \& Elwood, 2013). Further, hermit crabs that received a single shock within their shell showed a prolonged increase in motivation to leave that shell and move into a new one (Appel \& Elwood 2009a; Elwood \& Appel, 2009). They approached and investigated the new shell more quickly indicating an increased motivation for shell change (Elwood \& Stewart, 1985: Elwood, 1995).

Decapods also show prolonged rubbing or guarding of an affected area as seen in vertebrates (Weary et al., 2006). Glass prawns (Palaemon elegans) perform prolonged rubbing and grooming of the specific antenna brushed with either sodium hydroxide or acetic acid. (Barr et al., 2008). However, if the antenna is pre-treated with a local anaesthetic, the grooming and rubbing is much reduced. Prolonged abdominal grooming also occurs in hermit crabs (Pagurus bernhardus) after shock on the abdomen (Appel \& Elwood, 2009a Appel \& Elwood 2009b). Further, edible crabs (Cancer pagurus) with a cheliped (claw) removed by pulling it off (a practice used in commercial fisheries) repeatedly touch the

570 wound with their other appendages but not if they had been induced to autotomize the 
cheliped without a wound (McCambridge pers. comm). Further, formalin injection into one cheliped of shore crabs (Hemigrapsus sanguineus) induces shaking and rubbing of the appendage and the use of that appendage is markedly reduced (Dyuizen et al., 2012). Thus prolonged attention and guarding is common in decapods (but see Puri \& Faulkes, 2010). We note also that edible crabs that have had a claw pulled off causing tissue damage showed a marked prolonged physiological stress response whereas those induced to autotomize do not (Patterson et al., 2007).

Behavioural trade-offs between avoiding the noxious stimulus and retaining some other requirement has also been observed. Hermit crabs, for example, leave less preferred species of shell more readily compared to those in preferred species when subject to abdominal shock (Appel \& Elwood, 2009b,; Elwood \& Appel, 2009) and are less likely to evacuate shells after shock when odours of predators are present (Magee \& Elwood, unpublished).

Morphine has marked effects in reducing responsiveness to noxious stimuli in crabs, Chasmagnathus granulatus (Lozada et al., 1988), however, this does not appear to be due to analgesia but rather a general lack of response to any stimulus (Barr \& Elwood, 2011). Whilst analgesic effect has repeatedly demonstrated in vertebrates widely differing animals might use different regulating pain/nociceptive systems (Barr \& Elwood, 2011).

The prolonged rubbing and shaking of a cheliped injected with formalin noted above in H. sanguineus is accompanied by a gradual change in the central nervous system NO-ergic neurons that have been implicated in nociceptive reflexes in vertebrates and are present in primary sensory centres of crustaceans, insects and molluscs (reviewed in Dyuizen et al., 2012). These neurons were shown by expression of the enzyme nitric oxide synthase and this expression was earlier on the ipsilateral than on the contralateral side of the CNS indicating 
595

596

597

598

599

600

601

602

603

604

605

606

607

608

609

610

611

612

613

614

615

616

617

that it was due to a neuronal input from that side of the body. The earliest changes were seen in specific nerve fibres in the thoracic sensory neuropils and the most prominent seen in structures considered to modulate cheliped action. These changes occurred over a period of 30-60 minutes depending on location and showed far more than just an immediate reflex function. They are consistent with the idea of prolonged motivational change after noxious stimulation.

A recent study on crayfish (Procambarus clarkii) also noted long-term motivational change coupled with physiological change (Fossat et al., 2014). Some subjects were exposed to electrical fields that were aversive and induced attempted escape responses and then allowed to choose where to walk in a cross-shaped apparatus that had two arms in the light and two in the dark. All animals preferred the dark arms but those recently subjected to the aversive stimulus showed a stronger preference for the dark than did controls. Those subject to the electric field also had higher brain serotonin levels and a higher level of blood glucose, which has previously been recognised as a component of a stress response (Patterson et al., 2007). Control animals injected with serotonin also showed strong avoidance of light and increased glucose. Further, an anxiolytic drug abolished the light avoidance of stressed animals. The authors concluded that the stress-induced avoidance is similar to vertebrate anxiety and indicates the ability of invertebrates to exhibit a state similar to mammalian emotion.

\section{ARTHROPODS- INSECTS}

Insects respond vigorously to noxious stimuli, but these responses can be suppressed 
618 (e.g. during sexual cannibalism, Sakaluk et al., 2004) or intensified (e.g. after ultraviolet 619 exposure, Babcock et al., 2009). The molecular mechanisms mediating these behaviours are 620 at least partially known in some species (e.g. Drosophila melanogaster) and appear to be 621 homologous to the molecular mechanisms mediating nociception in mammals (Johnson \& 622 Carder, 2012). Nociception in insects, as in other invertebrates, is transduced by neurons dedicated to sensing damaging stimuli (nociceptors, Smith \& Lewin, 2009). D. melanogaster larvae have peripheral nociceptors that are studded with receptors sensitive to damaging stimuli (Tracey et al., 2003). The best studied of these receptors include transient receptor potential (TRP) channels such as the TRP channel "Painless" (Tracey et al., 2003) which is an evolutionary homolog of the mammalian TRPA1 (Smith \& Lewin, 2009). However, insects also differ from vertebrates in some ways in their responses to noxious stimuli. For example, insects tend to continue to use damaged limbs (Eisemann et al., 1984) and will selfcannibalize their own guts if injured (Lockwood, 2013).

How nociceptive information is processed within the insect central nervous system remains almost entirely unknown (Johnson \& Carder, 2012), although there is evidence that nociceptive information reaches higher learning centres in the insect brain (e.g. Waddell, 2013). Nociception in insects can be modified using simple peripheral mechanisms, without the involvement of the central nervous system (Johnson \& Carder, 2012). Therefore, simply showing that nociception is modifiable (e.g. by endogenous opioids or other molecules) is not a compelling argument that insects feel pain. Plasticity in responses to noxious stimuli does not necessarily indicate that an animal has the complex central nociceptive processing power required for the experience of 'pain'.

As in vertebrates, noxious stimuli can be used to 'teach' insects a variety of tasks 
642 learning studies (Tedjakumala \& Giurfa, 2013). Insects can also learn to avoid places 643 associated with noxious stimuli (Giurfa, 2013). They can also learn to associate otherwise 644 neutral stimuli with the cessation of electric shock and then prefer those stimuli, a 645 phenomenon called "pain relief learning" (Gerber et al., 2014). Therefore, insect nervous 646 systems are capable of assessing motivational variables and noxious stimuli can act as a 647 potent motivational force. (positive or negative) remains unclear. For example, a recent study in bees suggests that negative stimuli can induce pessimistic cognitive biases, as is observed in vertebrates (Bateson at al., 2011). However, Giurfa (2013) points out that Bateson et al.'s (2011) data equally support the interpretation that bees became better discriminators of a food reward after shaking (i.e. the negative stimulus used in Bateson's study). This alternative explanation is appealing because shaking alters octopamine concentrations in the hemolymph (Bateson et al., 2011), and octopamine levels are known to influence sensory function (Orchard et al., 1993; Roeder, 1999). Nevertheless, at present, there is no definitive evidence that insects have the prerequisite cognitive and emotional abilities to support a negative internal mental state.

With little neurobiological evidence for the existence of pain-like states in insects, we are left with trying to stretch the argument-by-analogy (Allen, 2011) to encompass the behaviour of this group. Insects may show behaviour that suggests an affective or motivational component (e.g. it has complex and long-lasting effects), but insects could do this, at least in some cases, by using mechanisms that require only nociception (e.g. long-term nociceptive sensitization) and/or advanced sensory processing (i.e. without any internal mental states). Moreover, recent advances in artificial intelligence (AI) have shown that 
robots can be programmed to express pain-like behaviour using relatively simple processing systems (e.g. Castro-González et al., 2013). The behaviour of these robots fulfils the behavioural criteria for pain listed in Table 2 (e.g. see Lee-Johnson \& Carnegie, 2010; Castro-González et al., 2013). For example, a robotic rodent has been programmed to experience 'discomfort' which can then be used as a learning motivator (Ames et al., 2012). AI researchers develop such 'emotional' robots because they recognize that affective processes give biological entities a great deal of cognitive flexibility (Lee-Johnson \& Carnegie, 2010). These 'emotional' robots have no subjectively experienced emotions, but the robot's artificial emotions allow it to reprioritize its goals, modulate its behaviour, and provide learning rewards (Lee-Johnson \& Carnegie, 2010; Castro-González et al., 2013). Similarly, insects, and possibly other animals, could use simple processing rules to produce pain-like behaviour, without any internal experience of pain.

\section{PRINCIPLE OF TRIANGULATION}

Pain in animals has been assessed using a wide range of indices, and it has been argued that none of these indices when taken in isolation can be considered as definitive evidence of 'pain' in animals (e.g. Rose et al. 2014). However, we along with other authors (e.g. Bateson 1991, Mason \& Mendl 1993, Sneddon 2004, 2009, 2011, 2013, Weary et al 2006, Nicol et al. 2009) are not advocating taking these individual isolated indices as evidence of pain, but that these indices should be taken together as representing an increasing level of complexity of responses to pain that go beyond simple and acute detection and reflex responses and begin to demonstrate a level of behavioural complexity that would require some form of experience. Pain is a complex multi-dimensional phenomenon (Rutherford 
690

691

692

693

694

695

696

697

698

699

700

701

702

703

704

705

706

707

708

709

710

711

712

713

2002), therefore in order to effectively identify and then assess the severity of pain may require a multi-modal approach. Ultimately we are advocating applying the principle of triangulation', where all of the indices are taken together as evidence of underlying affective state (Melissa Bateson, personal communication). Such a principle forms the foundation in many different scientific fields where a definitive answer cannot be directly measured. For example, the existence of dark matter in the universe, which cannot be measured directly but is inferred from gravitational effects of visible matter, radiation and the large scale structure of the universe (Trimble 1987).

\section{CONCLUSIONS}

Our summary of the evidence supports the conclusion that many animals can experience pain-like states by fulfilling our definition of pain in animals although we accept that $100 \%$ certainty cannot be established for any animal species. Nevertheless, the 'Precautionary principle', the idea that it is better to err on the side of more protection for a group of animals if it is beyond reasonable doubt that they experience pain (e.g. Andrews 2011), proposes that we should act as if at least some animals experience pain. From an ethical (Bateson, 2005) and often a legal perspective we must ensure the welfare of animals. Thus here we provide a basis for future studies to direct the investigation of pain in animals where evidence is lacking or inconclusive. This does not preclude the use of animals but careful consideration for the assessment and alleviation of pain is vital (Bateson, 2005). However, even if we cannot be certain that some species experience pain, they should be treated with respect for reasons that do not hinge on whether or not they experience pain (Harvey-Clark, 2011; Mather, 2011; Lockwood, 2013). 
Acknowledgements

716

717 We are grateful for comments from the editor, Ana Sendova-Franks and two anonymous reviewers. LUS is grateful for funding from EU FP7, NC3Rs, Society of Biology, Society for Endocrinology and UFAW.

\section{References}

722

723

724

725

726

727

728

729

730

731

732

733

734

735

Allen, C. (2004). Animal Pain. Nous, 38, 617-643.

Allen, C. (2011). Animal Consciousness. In: Stanford Encyclopedia of Philosophy (Ed. by E. N. Zalta), pp. 1-63. Stanford, CA: Metaphysics Research Lab.

Allen, C., Fuchs, P. N., Shriver, A. \& Wilson, H. D. (2005). Deciphering Animal Pain. In: Pain: new essays on its nature and the methodology of its study (Ed. by M. Aydede), pp. 351-366. Cambridge, MA: MIT Press.

Alupay, J.S., Hadjisolomou, S.P. \& Crook, R.J. (2014). Arm injury produces long-term behavioural and neural hypersensitivity in octopus. Neuroscience Letters 558, 137142.

Alves, F.L., Barbosa Júnior, A. \& Hoffmann, A. (2013) Antinociception in piauçu fish induced by exposure to the conspecific alarm substance. Physiology \& Behavior 110-111, 58-62.

Ames, H., Mingolla, E., Sohail, A., Chandler, B., Gorchetchnikov, A., Leveille, J., Livitz, G. \& Versace, M. (2012). The Animat New Frontiers in Whole Brain Modeling. Ieee Pulse, 3, 4750.

Andrews, P. L. R. (2011). Laboratory Invertebrates: Only spineless or spineless and painless. ILAR 
Appel, M. \& Elwood, R.W. (2009a). Gender differences, responsiveness and memory of a potentially painful event in hermit crabs. Animal Behaviour, 78, 1373-1379.

Appel, M. \& Elwood, R.W. (2009b). Motivational trade-offs and the potential for pain experience in hermit crabs. Applied Animal Behaviour Science 119, 120-124.

Arras, M., Rettich, A., Cinelli, P., Kasermann, H. P., \& Burki, K. (2007). Assessment of postlaparotomy pain in laboratory mice by telemetric recording of heart rate and heart rate variability. BMC Veterinary Research, 3, 16.

Ashley, F. H., Waterman-Pearson, A. E., \& Whay, H. R. (2005). Behavioural assessment of pain in horses and donkeys: application to clinical practice and future studies. Equine Veterinary Journal, 37(6), 565-575.

Ashley, P.J., Sneddon, L.U. \& McCrohan, C.R. (2007). Nociception in fish: stimulusresponse properties of receptors on the head of trout Oncorhynchus mykiss. Brain Research 1166, 47-54.

Ashley. P.J., Sneddon, L.U. \& McCrohan, C.R. (2006). Properties of corneal receptors in a teleost fish. Neuroscience Letters 410, 165-168.

Ashley, P.J., Ringrose, S., Edwards, K.L., McCrohan, C. R. \& Sneddon, L.U. (2009). Effect of noxious stimulation upon antipredator responses and dominance status in rainbow trout. Animal Behaviour 77, 403-410.

Babcock, D. T., Landry, C. \& Galko, M. J. (2009). Cytokine Signaling Mediates UV-Induced Nociceptive Sensitization in Drosophila Larvae. Current Biology, 19, 799-806.

Barr, S. \& Elwood, R.W. (2011). No evidence of morphine analgesia to noxious shock in the shore crab, Carcinus maenas. Behavioural Processes, 86, 340-344. 
Barr, S., Laming, P.R., Dick, J.T.A. \& Elwood, R.W. (2008). Nociception or pain in a decapod crustacean? Animal Behaviour , 75, 745-751.

Bateson, P. (1991). Assessment of pain in animals. Animal Behaviour 42, 827-839.

Bateson, P. (2005). Ethics and Behavioral Biology. Advances in the Study of Behavior, 35, $211-233$

Bateson, M., Desire, S., Gartside, S. E. \& Wright, G. A. (2011). Agitated honeybees exhibit pessimistic cognitive biases. Current Biology, 21, 1070-1073.

Berg, H. C. (1975). Chemotaxis in bacteria. Annual Review of Biophysics and Bioengineering, 4, 119-136.

Bermond, B. (1997) The myth of animal suffering. In: Animal Consciousness and Animal Ethics, (Eds. M. Dol, S. Kasanmoentalib, S. Lijmbach, E. Rivas, R. van den Bos), Van Gorcum, Assen, The Netherlands, pp. 125-143.

Bermond, B. (2001). A neuropsychological and evolutionary approach to animal consciousness and animal suffering. Animal Welfare 10, S47-S62.

Berthier, M., Starkstein, S. \& Leiguarda, R. (1987). Behavioral effects of damage to the right insula and surrounding regions. Cortex 23, 673-678.

Bjørge, M.H., Nordgreen, J., Janczak, A.M., Poppe, T., Ranheim, B. \& Horsberg, T.E. (2011). Behavioural changes following intraperitoneal vaccination in Atlantic salmon (Salmo salar). Applied Animal Behaviour Science 133, 127-135.

Breazeal, C. (2011). Social Robots for Health Applications. 2011 Annual International Conference of the IEEE Engineering in Medicine and Biology Society, 5368-5371.

Breward, J. \& Gentle, M.J. (1985). Neuroma formation and abnormal afferent nerve discharges after partial beak amputation (beak trimming) in poultry. Experientia 41, 1132-1134. 
Brilot B.O., Asher L., Bateson M. (2010) Stereotyping starlings are more 'pessimistic'. Animal Cognition 13, 721-731.

Broom, D.M. (1998). Welfare, stress, and the evolution of feelings. Advances in the Study of Behaviour 27, 371-403.

Broom, D.M. (2001). Evolution of pain. In: Pain: Its nature and management in man and animals. Royal Society of Medicine International Congress Symposium Series. Vol. 246 (Ed. by E. J. L. Lord Soulsby \& D. Morton), pp. 17-25. London: Royal Society of Medicine.

Cambridge Declaration on Consciousness 2012 (2012).

\section{http://fcmconference.org/img/CambridgeDeclarationOnConsciousness.pdf}

Cameron, A.A., Plenderleith, M.B. \& Snow, P.J. (1990). Organisation of the spinal cord in four species of elasmobranch fish: cytoarchitecture and distribution of serotonin and selected neuropeptides. Journal of Comparative Neurology, 297, 201-218.

Castro-González, A., Malfaz, M. \& Salichs, A. (2013). An autonomous social robot in fear. IEEE Transactions on Autonomous Mental Development, 5, 135-151.

Chase, R. (2002). Behavior and its Neural Control in Gastropod Molluscs. Oxford University Press, Oxford.

Carstens, E. \& Moberg, G.P. (2000). Recognizing pain and distress in laboratory animals. ILAR Journal 41, 62-71.

Colpaert, F.C., De Witte, P., Marole, A.N., Awouters, F., Niemegeers, E. \& Janssen, P.A.J. (1980). Self-administration of the analgesic suprofen in arthritis rats: Mycobacterium butyricum-induced arthritis as an experiment model of chronic pain. Life Sciences 27: 921-928. 
Correia, A.D., Cunha, S.R., Scholze, M. \& Stevens, E.D. (2011). A novel behavioral fish model of nociception for testing analgesia. Pharmaceuticals 4: 665-680.

Crook, R.J., Lewis, T., Roger T. Hanlon, R.T. \& Walters, E.T. (2011). Peripheral injury induces long-term sensitization of defensive responses to visual and tactile stimuli in the squid Loligo pealeii, Lesueur 1821. Journal of Experimental Biology 214, 31733185

Crook, R.J., Hanlon, R.T. \& Walters, E.T. (2013). Squid have nociceptors that display widespread long-term sensitization and spontaneous activity after bodily injury. Journal of Neuroscience 33 10021-10026.

Crook, R.J., Dickson, K., Hanlon, R.T. \& Walters, E.T. (2014). Nociceptive sensitization reduces predation risk. Current Biology 24, 1121-1125.

Dalla Costa, E. Minero, M., Lebelt, D., Stucke, D., Canlai, E. \& Leach, M.C. (2014) Development of the Horse Grimace Scale (HGS) as a pain assessment tool in horses undergoing routine castration. PLoS ONE, 9, e92281.

Danbury, T.C., Weeks, C.A., Chambers, J.P., Waterman-Pearson, A.E. \& Kestin, S.C., (2000). Self-selection of the analgesic drug carprofen by lame broiler chickens. Veterinary Record 146, 307-311.

Davis, G.S., Anderson, K.E. \& Jones, D.R. (2004). The effects of different beak trimming techniques on plasma corticosterone and performance criteria in single comb white leghorn hens. Poultry Science 83, 1624-1628.Dawkins, M.S. (1980). Animal suffering: The science of animal welfare. London: Chapman and Hall. 
Douglas C., Bateson M., Walsh C, Bédué A. \& Edwards S.A. (2012). Environmental enrichment induces optimistic cognitive biases in pigs. Applied Animal Behaviour Science 139, 65-73.

Dubbeldam, J.L. (2009) The Trigeminal System in Birds and Nociception Central Nervous System Agents. Medicinal Chemistry 9, 150-158.

Dunlop, R. \& Laming, P. (2005). Mechanoreceptive and nociceptive responses in the central nervous system of goldfish (Carassius auratus) and trout (Oncorhynchus mykiss). Journal of Pain 6, 561-568.

Dunlop, R., Millsopp, S. \& Laming, P. (2006). Avoidance learning in goldfish (Carassius auratus) and trout (Oncorhynchus mykiss) and implications for pain perception. Applied Animal Behaviour Science 97, 255-271.

Dyuizen, I.V., Kotsyuba, E.P \& Lamash, N.E. (2012). Changes in the nitric oxide system in the shore crab Hemigrapsus sanguineus (Crustacea, decapoda) CNS induced by a nociceptive stimulus. Journal of Experimental Biology 215, 2668-2676.

Ehrensing, R.H., Michell, G.F. \& Kastin, A.J. (1982). Similar antagonism of morphine analgesia by MIF-1 and naloxone in Carassius auratus. Pharmacology, Biochemistry and Behavior 17, 757-761.

Eisemann, C.H., Jorgensen, W.K., Merritt, D.J., Rice, M.J., Cribb, B.W., Webb, P D. \& Zalucki,M. P. (1984). Do insects feel pain? - A biological view. Experientia 40, 164-167.

Ekman, P. \& Friesen, W.V. (1978). Facial action coding system: A technique for the measurement of facial action. Consulting Psychologists Press, Palo Alto.

Elwood, R.W. (1995). Motivational change during resource assessment in hermit crabs. Journal of Experimental Marine Biology and Ecology 193, 41-55. 
Elwood, R.W. (2011). Pain and suffering in invertebrates? ILAR Journal 52, 175-184.

851 Elwood, R.W. (2012). Evidence for pain in decapod crustaceans. Animal Welfare 21, 23-27.

852 Elwood, R.W. \& Appel, M. (2009). Pain in hermit crabs? Animal Behaviour 77, 1243-1246.

853 Elwood, R.W., Barr, S. \& Patterson, L. (2009). Pain and stress in crustaceans? Applied Animal Behaviour Science 118, 128-136.

Elwood, R.W. \& Stewart, A. (1985). The timing of decisions during shell investigation by the hermit crab, Pagurus bernhardus. Animal Behaviour 33, 620-627.

Evrard, H.C. \& Balthazart, J. (2002). The assessment of nociceptive and non-nociceptive skin sensitivity in the Japanese quail (Coturnix japonica). Journal of Neuroscience Methods

116, 135-146.Faulkner, P. M. \& Weary, D.M. (2000). Reducing pain after dehorning in dairy 861 calves. Journal of Dairy Science 83, 2037-2041.

Flecknell, P., Gledhill, J. \& Richardson, C. (2007). Assessing animal health and welfare and

Flecknell, P., Leach, M., \& Bateson, M. (2011). Affective state and quality of life in mice. Pain 152(5), 963-964.

Fossat, P., Bacqué-Cazenave, J., De Deurwaerdère, P., Delbecque, J-P. \& Cattaert, D. (2014) Anxiety-like behavior in crayfish is controlled by serotonin. Science 344, 1293-1297.

Freire, R. \& Glatz, P.C. (2008). Self-administration of an analgesic does not alleviate pain in beak trimmed chickens. Asian-Australasian Journal of Animal Sciences 21, 443-448. 
Gao, Y.J., Ren, W.H., Zhang Y.Q., \& Zhao ZQ (2004). Contributions of the anterior cingulate cortex and amygdala to pain-and fear-conditioned place avoidance in rats. Pain 110, 343-353.

Geelen, S., Sanchez-Migallon Guzman, D., Souza, M.J., Cox, S., Keuler, N.S. \& PaulMurphy, J.R. (2013). Anti nociceptive effects of tramadol hydrochloride after intravenous administration to Hispaniolan Amazon parrots (Amazona ventralis). American Journal of Veterinary Research 74, 201-206.

Gentle, M.J. \& Hill, F.L. (1987). Oral lesions in the chicken: behavioural responses following nociceptive stimulation. Physiology and Behavior 40, 781-783.

Gentle, M.J. \& Hunter, L.N. (1991). Physiological and behavioural responses associated with feather removal in Gallus gallus var domesticus. Research in Veterinary Science 50, 95-101.

Gentle, M.J. \& Tilston, V.L. (2000). Nociceptors in the legs of poultry: implications for potential pain in pre-slaughter shackling, Animal Welfare 9, 227-236.

Gentle, M.J., Bradbury, J.M. \& Wilson, S. (2003). Sensory properties of articular

afferents following Mycoplasma arthritis in the chicken. Brain Research 968, 26-34.

Gentle, M.J., Tilston, V.\& McKeegan, D.E. (2001). Mechanothermal nociceptors

in the scaly skin of the chicken leg. Neuroscience 106, 643-652.

Gerber, B., Yarali, A., Diegelmann, S., Wotjak, C.T., Pauli, P. \& Fendt, M. (2014). Painrelief learning in flies, rats, and man: basic research and applied perspectives. Learning and Memory 21, 232-252.

891 Giurfa, M. (2013). Cognition with few neurons: higher-order learning in insects. Trends in 
Glatz, P.C. (1987) Effects of beak trimming and restraint on heart rate, food intake, body weight and egg production in hens. British Poultry Science 28, 601-611.

Glatz, P.C. \& Lunam, C.A. (1994). Production and heart-rate responses of chickens beaktrimmed at hatch or at 10 or 42 days of age. Australian Journal of Experimental Agriculture 34, 443-447.

Goldkuhl, R., Hau, J. \& Abelson, K.S.P. (2010). Effects of voluntarily-ingested buprenorphine on plasma corticosterone levels, body weight, water intake, and behaviour in permanently catheterised rats. In Vivo 24, 131-135.

Gritsai, O. B., Dubynin, V. A., Pilipenko, V. E. \& Petrov, O. P. (2004). Effects of peptide and nonpeptide opioids on protective reaction of the cockroach Periplaneta americana in the "hot camera". Journal of Evolutionary Biochemistry and Physiology, 40, 153-160.

Guénette, S.A., Giroux, M. \& Vachon, P. (2013). Pain perception and anaesthesia in research frogs. Experimental Animals 62, 87-92.

Harvey-Clark, C. (2011). IACUC challenges in invertebrate research. ILAR Journal, 52, 213-220.

Hellebrekers, L.J., Kemme R.M.F.J. \& vanWandelen R.W. (1994). Nalbuphine as a postoperative analgesic in the dog: a comparison with buprenorphine. Journal of Veterinary Anaesthesia 21, 40.

Hess, A. Sergejeva, M., Budinsky, L., Zeilhofer, H.U. \& Brune, K. (2007). Imaging of hyperalgesia in rats by functional MRI. European Journal of Pain 11, 109-119.

Holton, L. L., Scott, E. M., Nolan, A. M., Reid, J., \& Welsh, E. (1998). Relationship between physiological factors and clinical pain in dogs scored using a numerical rating scale. Journal of Small Animal Practice, 39(10), 469-474. 
Hothersall, B., Caplen, G., Nicol, C.J., Taylor, P.M., Waterman-Pearson, A.E., Weeks, C.A. \& Murrell J.C. (2011). Development of mechanical and thermal nociceptive threshold testing devices in unrestrained birds (broiler chickens). Journal of Neuroscience Methods 201, 220- 227.

Im, S.H. \& Galko, M.J. (2012). Pokes, sunburn, and hot sauce: Drosophila as an emerging model for the biology of nociception. Developmental Dynamics 241, 16-26.

Johnson, W. A. \& Carder, J. W. (2012). Drosophila nociceptors mediate larval aversion to dry surface environments utilizing both the painless TRP channel and the DEG/ENaC subunit, PPK1. Plos One, 7, e32878.

Jordt, S. \& Julius, D. (2002). Molecular basis for species-specific sensitivity to "hot" chili peppers. Cell 108, 421-430.

Kanetoh, T., Sugikawa, T., Sasaki, I., Muneoka, Y., Minakata, H., Takabatake, I. \& Fujimoto, M. (2003). Identification of a novel frog RFamide and its effect on the latency of the tail-flick response of the newt. Comparative Biochemistry and Physiology Part C 134, 259-266.

Kalliokoski, O., Abelson, K. S., Koch, J., Boschian, A., Thormose, S. F., Fauerby, N. \& Hau, J. (2010). The effect of voluntarily ingested buprenorphine on rats subjected to surgically induced global cerebral ischaemia. In Vivo 24, 641-646.

Kavaliers, M. (1988). Evolutionary and comparative aspects of nociception. Brain Research Bulletin 21, 923-931.

Keating, C.J., Thomas, A.A., Flecknell, P.A. \& Leach, M.C. (2012). Evaluation of EMLA cream for preventing pain during tattooing of rabbits: changes in physiological, behavioural and facial expression responses. PLOS ONE 7,: e44437. 
Kent, J.E., Molony, V. \& Robertson, I.S. (1993). Changes in plasma cortisol concentration in lambs of three ages after three methods of castration and tail docking. Research in Veterinary Sciences 55 246-251.

Kicliter, E. \& Ebbesson, S.O.E. (1976). Organization of the non-olfactory telencephalon. pp. 946-974. In: Frog Neurobiology: A Handbook (Llinas, R. and Precht, W. eds.), Springer-Verlag, Berlin.

Kischinovsky, M., Duse, A., Wang, T. \& Bertelsen, M.F. (2013). Intramuscular administration of alfaxalone in red-eared sliders (Trachemys scripta elegans) - effects of dose and body temperature. Veterinary Anaesthesia and Analgesia 40, 13-20.

Kitchener. P.D., Fuller, J. \& Snow, P.J. (2010). Central projections of primary sensory afferents to the spinal dorsal horn in the long-tailed stingray, Himantura fai Brain Behavior and Evolution 76, 60-70.Langford, D.J., Bailey, A.L., Chanda, M.L., Clarke, S.E., Drummond TE, et al., (2010). Coding of facial expressions of pain in the laboratory mouse. Nature Methods 7,447-449.

Leach, M.C., Allweiler, S., Richardson, C., Roughan, J. V., Narbe, R., \& Flecknell, P.A. (2009). Behavioural effects of ovariohysterectomy and oral administration of meloxicam in laboratory housed rabbits. Research in Veterinary Science 87, 336-347.

Leach, M.C., Klaus, K., Miller, A. L., di Perrotolo, M.S., Sotocinal, S. G., \& Flecknell, P. A. (2012). The assessment of post-vasectomy pain in mice using behaviour and the Mouse Grimace Scale. PloS One 7(4), e35656.

Lee-Johnson, C. P. \& Carnegie, D. A. (2010). Mobile Robot Navigation Modulated by Artificial Emotions. Ieee Transactions on Systems Man and Cybernetics Part B-Cybernetics, 40, 469480. 
962 Leslie, E., Hernández-Jover, M., Newman, R., \& Holyoake, P. (2010). Assessment of acute pain experienced by piglets from ear tagging, ear notching and intraperitoneal injectable transponders. Applied Animal Behaviour Science 127(3), 86-95.

965

966

967

968

969

970

971

972

973

974

975

976

977

978

979

980

981

982

Liang, Y.F. \& Terashima, S. (1993). Physiological properties and morphological characteristics of cutaneous and mucosal mechanical nociceptive neurons with Adelta peripheral axons in the trigeminal ganglia of crotaline snakes, Journal of Comparative Neurology 328, 88-102.

Liles, J. H., Flecknell, P.A., Roughan, J. \& Cruz-Madoran, I. (1998). Influence of oral buprenorphine, oral naltrexone, or morphine on the effects of laparotomy in the rat. Laboratory Animals 32, 149-161.

Lockwood, J. (2013). Do bugs feel pain? : OUPblog. http://blog.oup.com/2011/11/bug-pain/ Lozada, M., Romano, A. \& Maldonado, H. (1988). Effects of morphine and naloxone on a defensive response of the crab Chasmagnathus granulatus. Pharmacology Biochemistry and Behaviour 30, 635-640.

Magee, B. \& Elwood, R.W. (2013). Shock avoidance by discrimination learning in the shore crab (Carcinus maenas) is consistent with a key criterion for pain. Journal of Experimental Biology, 216, 353-358.

Mason G. \& Mendl M. (1993) Why is there no simple way of measuring animal welfare? Animal Welfare 2, 301-309.

Mather, J. A. 2011. Philosophical background of attitudes toward and treatment of invertebrates. ILAR Journal, 52, 205-212. 
Matson, D.J., Broom, D.C., Carson, S.R., Baldassari, J., Kehne, J. \& Cortright, D.N. (2007). Inflammation-induced reduction of spontaneous activity by adjuvant: A novel model to study the effect of analgesics in rats. Journal of Pharmacology and Experimental Therapeutics 320, 194-201.

Maximino, C. (2011). Modulation of nociceptive-like behavior in zebrafish (Danio rerio) by environmental stressors. Psychology \& Neuroscience, 4, $149-155$.

McKeegan, D.E., Demmers, T.G., Wathes, C.M., Jones, R.B. \& Gentle, M.J. (2002). Response characteristics of nasal trigeminal nociceptors in Gallus domesticus. NeuroReport 13, 1033-1035.

McKeegan, D.E. (2004). Mechano-chemical nociceptors in the avian trigeminal mucosa. Brain Research Reviews 46, 146-154.

Mellor, D. J., Stafford, K. J., Todd, K. S., Jr., Lowe, TE, Gregory, N. G, Bruce, R. A. \& Ward, R. N. (2002). A comparison of catecholamine and cortisol responses of young lambs and calves to painful husbandry procedures. Australian Veterinary Journal 80, $228-233$

Mendl, M., Burman, O.H.P., Parker, R.M.A. \& Paul, E.S. (2009). Cognitive bias as an indicator of animal emotion and welfare: Emerging evidence and underlying mechanisms. Applied Animal Behavior Science 118, 161-181.

Mettam, J.M., Oulton, L.J., McCrohan, C.R. \& Sneddon, L.U. (2011). The efficacy of three types of analgesic drug in reducing pain in the rainbow trout, Oncorhynchus mykiss. Applied Animal Behaviour Science 133, 265-274.

Millsopp, S. \& Laming, P. (2008). Trade-offs between feeding and shock avoidance in goldfish (Carassius auratus). Applied Animal Behaviour Science 113, 247-254. 
Mohan, S.K. \& Stevens, C.W. (2006). Systemic and spinal administration of the mu opioid,

1007

1008

1009

1010

1011

1012

1013

1014

1015

1016

1017

1018

1019

1020

1021

1022

1023

1024

1025

1026

1027

remifentanil, produces antinociception in amphibians. European Journal of Pharmacology $534,89-94$.

Molony, V. \& Kent, J. E. (1997). Assessment of acute pain in farm animals using behavioral and physiological measurements. Journal of Animal Science 75(1), 266-272.

Molony, V., Kent, J. E., \& Robertson, I. S. (1995). Assessment of acute and chronic pain after different methods of castration of calves. Applied Animal Behaviour Science 46(1), 33-48.

Mosley, C. (2011). Pain and nociception in reptiles Veterinary Clinics of North America Exotic Animal Practice 14, 45-60.

Mosley C. 2006 Pain, nociception and analgesia in reptiles: when your snake goes “ouch!" The North American Veterinary Conference 2006, 1652 - 1653.

Nasr, M.A.F., Nicol C.J. \&, Murrell, J.C. (2012). Do laying hens with keel bone fractures experience pain? PLoS One 7. e42420.

Neely, G.C., Hess, A., Costigan, M., Keene, A.C., Goulas, S., Langeslag, M., et al. (2010) A genome-wide Drosophila screen for heat nociception identifies $\alpha 2 \delta 3$ as an evolutionarily conserved pain gene. Cell 143, 628-638.

Newby, N.C., Wilkie, M.P. \& Stevens, E.D. (2009). Morphine uptake, disposition, and analgesic efficacy in the common goldfish (Carassius auratus). Canadian Journal of Zoology 87, 388-399.

Nicol C., Caplen G., Edgar J., \& Browne W. (2009). Associations between welfare indicators and environ $\neg$ mental choice in laying hens. Animal Behaviour, 78, 413-424. 
Nordgreen, J., Horsberg, T.E., Ranheim, B. \& Chen, A.C.N. (2007). Somatosensory evoked potentials in the telencephalon of Atlantic salmon (Salmo salar) following galvanic stimulation of the tail. Journal of Comparative Physiology Part A 193, 1235-1242.

Orchard, I., Ramirez, J. M. \& Lange, A. B. (1993). A multifunctional role for octopamine in locust flight. Annual Review of Entomology, 38, 227-249.

Patterson, L., Dick, J.T.A., Elwood, R.W. (2007). Physiological stress responses in the edible crab. Cancer pagurus, to the fishery practice of de-clawing. Marine Biology 152, $265-272$.

Peers, A., Mellor, D. J., Wintour, E. M., and Dodic, M (2002). Blood pressure, heart rate, hormonal and other acute responses to rubber ring castration and tail docking of lambs. New Zealand Veterinary Journal 50, 56-62.

Pham, T. M., Hagman, B., Codita, A., Van Loo, P. L. P., Strommer, L. \& Baumans, V. (2010). Housing environment influences the need for pain relief during post-operative recovery in mice. Physiology \& Behavior, 99, 663-668.

Pinel, J.P.J., Symons, L.A., Christensen, B.K. \& Tees, R.C. (1989). Development of defensive burying in Rattus norvegicus: Experience and defensive responses. Journal of Comparative Psychology 103, 359-365.

Pritchett, L.C., Ulibarri, C., Roberts, M.C., Schneider, R.K. \& Sellon, D.C. (2003). Identification of potential physiological and behavioral indicators of postoperative pain in horses after exploratory celiotomy for colic. Applied Animal Behaviour Science 80, 31-43. 
Prunier, A., Mounier, L., Le Neindre, P., Leterrier, C., Mormède, P., Paulmier, V., Prunet, P., Terlouw, C. \& Guatteo, R. (2013). Identifying and monitoring pain in farm animals: a review. Animal 7, $998-1010$.

Puri, S. \& Faulkes, Z. (2010). Do decapod crustaceans have nociceptors for extreme pH? PLoS One 5, e10244.

Purves, D., Augustine, G. J., Fitzpatrick, D., Hall, W. C., Lamantia, A. S. \& White, L. E. (2012). Neuroscience, 5th edn. Sunderland, MA: Sinauer.

Raekallio M., Taylor P.M., Bloomfield M. (1997). A comparison of methods for evaluation of pain and distress after orthopaedic surgery in horses. Veterinary Anaesthesia and Analgesia 24, I 17-20

Reilly, S.C., Quinn, J.P., Cossins, A.R. \& Sneddon, L.U. (2008a). Behavioural analysis of a nociceptive event in fish: comparisons between three species demonstrate specific responses. Applied Animal Behaviour Science 114, 248-259.

Reilly, S.C., Quinn, J.P., Cossins, A.R. \& Sneddon, L.U. (2008b). Novel candidate genes identified in the brain during nociception in common carp (Cyprinus carpio) and rainbow trout (Oncorhynchus mykiss). Neurosci. Lett. 437, 135-138.

Rink, E. \& Wullimann, M.F. (2004).Connections of the ventral telencephalon (subpallium) in the zebrafish (Danio rerio), Brain Research 1011, 206-220.

Roach, J.T. \& Sufka, K.J. (2003). Characterization of the chick carrageenan response. Brain Research 994, 216-225

Robertson, I.S., Kent, J.E. \& Molony, V. (1994). Effect of different methods of castration on behaviour and plasma cortisol in calves of three ages. Research in Veterinary Sciences $56,8-17$ 
Roeder, T. (1999). Octopamine in invertebrates. Progress in Neurobiology, 59, 1-31.

Roques, J.A.C., Abbink, W., Geurds, F., van de Vis, H. \& Flik, G. (2010) Tailfin clipping, a painful procedure: studies on Nile tilapia and common carp. Physiology and Behavior $101,533-540$.

Rose, J.D. (2002). The neurobehavioral nature of fishes and the question of awareness and pain. Reviews in Fisheries Science 10, 1-38

Rose, J.D., Arlinghaus, R., Cooke, S.J., Diggles, B.K., Sawynok, W., Stevens, E.D. \& Wynne, C.D.L. (2014). Can fish really feel pain? Fish and Fisheries 15, 97-133.

Roughan, J. V. and Flecknell P.A. (2000). Effects of surgery and analgesic administration on spontaneous behavior in singly housed rats. Research in Veterinary Science 69, 283288.

Roughan, J. V. \& Flecknell P.A. (2001). Behavioural effects of laparotomy and analgesic effects of ketoprofen and carprofen in rats. Pain 90, 65-74.

Roughan, J. V. \& Flecknell, P. A. (2003). Evaluation of a short duration behaviour-based post-operative pain scoring system in rats. European Journal of Pain 7(5), 397-406.

Rutherford, K. M. D. (2002). Assessing pain in animals. Animal Welfare 11, 31-53.

Sakaluk, S. K., Campbell, M. T. H., Clark, A. P., Johnson, J. C. \& Keorpes, P. A. (2004). Hemolymph loss during nuptial feeding constrains male mating success in sagebrush crickets. Behavioral Ecology, 15, 845-849.

Sanchez-Migallon Guzman, D., Drazenovich, T.L., Olsen, G.H., Willits, N.H. \& Paul-Murphy, J.R. (2013). Evaluation of thermal antinociceptive effects after intramuscular administration of hydromorphone hydrochloride to American kestrels (Falco sparverius). American Journal of Veterinary Research 74, 817-822. 
Sapolsky, R. M., Romero, L. M. \& Munck, A.U. (2000). How do glucocorticoids influence stress responses? Integrating permissive, suppressive, stimulatory, and preparative actions. Endocrinology Reviews 2155-89.

Sherwin, C. M. (2001). Can invertebrates suffer? Or, how robust is argument-by-analogy. Animal Welfare, 10, S103-S118.

Shriver, A. (2006). Minding mammals. Philosophical Psychology 19, 433-442.

Sladky, K.K., Kinney, M.E. \& Johnson, S.M. (2008) Analgesic efficacy of butorphanol and

morphine in bearded dragons and corn snakes. Journal of the American Veterinary Medical Association 233, 267-273.

Sladky, K.K., Miletic, V., Paul-Murphy, J., Kinney, M.E., Dallwig, R.K. \& Johnson, S.M. (2007) Analgesic efficacy and respiratory effects of butorphanol and morphine in turtles. Journal of the American Veterinary Medical Association, 230, 1356-1362.

Slingsby, L.S. \& Waterman-Pearson, A.E. (1998). Comparison of pethidine, buprenorphine and ketoprofen for postoperative analgesia after ovariohysterectomy in the cat, Veterinary Record 143, 185-189.

Smith, E. S. J. \& Lewin, G. R. (2009). Nociceptors: a phylogenetic view. Journal of Comparative Physiology Part A 195, 1089-1106.

Sneddon, L.U. (2002). Anatomical and electrophysiological analysis of the trigeminal nerve in a teleost fish, Oncorhynchus mykiss. Neuroscience Letters 319, 167-171.

Sneddon, L.U. (2003a). Trigeminal somatosensory innervation of the head of a teleost fish with particular reference to nociception. Brain Research 972, 44-52.

Sneddon L.U. (2003b). The evidence for pain in fish: the use of morphine as an analgesic. Applied Animal Behaviour Science 83, 153- 162. 
Sneddon, L.U. (2004). Evolution of nociception in vertebrates: comparative analysis of lower vertebrates. Brain Research Reviews 46, 123-130.

Sneddon, L.U. (2009). Pain perception in fish:indicators and endpoints. ILAR Journal 50, $338-342$.

Sneddon, L.U. (2011). Pain perception in fish: Evidence and implications for the use of fish. Journal of Consciousness Studies 18, 209-229.

Sneddon, L.U. (2013). Do painful sensations and fear exist in fish. In Animal Suffering: From Science to Law, International Symposium (Eds T.A van der Kemp \& M. Lachance) pp 93-112, Carswell, Toronto.

Sneddon, L.U., Braithwaite, V.A. \& Gentle, M.J. (2003a). Novel object test: examining nociception and fear in the rainbow trout. Journal of Pain 4, 431-440.

Sneddon, L.U., Braithwaite, V.A. \& Gentle, M.J. (2003b). Do fishes have nociceptors? Evidence for the evolution of a vertebrate sensory system. Proceedings of the Royal Society of London B 270, 1115-1121.

Snow, P. J., Plenderleith, M. B. \& Wright, L. L. (1993). Quantitative study of primary sensory neurone populations of three species of elasmobranch fish. Journal of Comparative Neurology 334, 97-103.

Sotocinal, S. G., Sorge, R. E., Zaloum, A., Tuttle, A. H., Martin, L. J., Wieskopf, J. S. \& Mogil, J. S. (2011). The Rat Grimace Scale: a partially automated method for quantifying pain in the laboratory rat via facial expressions. Molecular Pain, 7(1), 55. 
Sprecher, D. J., Hostetler, D.E. \& Kanneene J. B. (1997). A lameness- scoring system that uses posture and gait to predict dairy cattle reproductive performance. Theriogenology 47, 1179-1187.

Stamp Dawkins, M. (2012). Why animals matter. Animal consciousness, animal welfare, and human well-being. Oxford: Oxford University Press.

Stanway, G. W., Taylor, P. M. \& Brodbelt, D. C. (1996). A comparison of pre-operative morphine and buprenorphine in cats. Journal of Veterinary Anaesthesia 23, 78.

Stevens , C.W., Martin, K.K. \& Stahlheber, B.W. (2009). Nociceptin produces antinociception after spinal administration in amphibians. Pharmacology, Biochemistry and Behavior 91, 436-440.

Stockman, J., Weber III, E.S.P., Kass, P.H., Pascoe, P.J. \& Paul-Murphy, J. (2013). Physiologic and biochemical measurements and response to noxious stimulation at various concentrations of MS-222 in Koi (Cyprinus carpio). Veterinary Anaesthesia and Analgesia 40, 35-47.

Taylor, A.A. \& Weary, D.M. (2000). Vocal response of piglets to castration: identifying procedural sources of pain. Applied Animal Behaviour Science 70, 17-26.

Tedjakumala, S. R. \& Giurfa, M. 2013. Rules and mechanisms of punishment learning in honey bees: the aversive conditioning of the sting extension response. Journal of Experimental Biology, 216, 2985-2997.

Terashima, S. \& Liang, Y. (1994). C mechanical nociceptive neurons in the crotaline trigeminal ganglia. Neuroscience Letters 179, 33-36.

Thornton, P. D. \& Waterman-Pearson, A.E. (1999). Quantification of the pain and distress responses to castration in young lambs. Research in Veterinary Science 66, 107-118. 
Tobin, D.M. \& Bargmann, C.L. (2004). Invertebrate nociception: behaviors, neurons and molecules. Journal of Neurobiology 61, 161-174.

Tracey, W. D., Wilson, R. I., Laurent, G. \& Benzer, S. (2003). Painless, a Drosophila gene essential for nociception. Cell, 113, 261-273.

Trimble, V. (1987). Existence and nature of dark matter in the universe. Annual Review of Astronomy and Astrophysics 25, 425-472.

Tsagareli, M. G. (2011). Behavioral testing of the effects of thermosensitive trp channel agonists on touch, temperature, and pain sensations. Neurophysiology, 43, 309-320.

Vesselkin, N.P., Agayan, A.L. \& Nomokovona, L.M. (1971). A study of thalamotelencephalic afferent systems in frogs. Brain Behavior and Evolution 4, 295-306.

Waddell, S. (2013). Reinforcement signalling in Drosophila; dopamine does it all after all. Current Opinion in Neurobiology 23, 324-329.

Wambugu, S.N., Towett, P.K., Kiama, S.G., Abelson, K.S.P. \& Kanui, T.I. (2010). Effects of opioids in the formalin test in the Speke's hinged tortoise (Kinixy's spekii). Journal of Veterinary Pharmacological Therapy 33, 347-351.

Weary, D.M., Neil, L., Flower, F.C. \& Fraser, D. (2006). Identifying and preventing pain in animals. Applied Animal Behaviour Science 100, 64-76.

Wheeler-Aceto, H. \& Cowan, A. (1991). Standardization of the rat paw formalin test for the evaluation of analgesics. Psychopharmacology, 104, 35-44.

Willenbring, S. \& Stevens, W. (1996). Thermal, mechanical and chemical peripheral sensitization in amphibians: Opioid and adrenergic effects. Life Sciences 58, 125-133. 
Wittenburg, N. \& Baumeister, R. (1999). Thermal avoidance in Caenorhabditis elegans: An approach to the study of nociception. Proceedings of the National Academy of Sciences of the United States of America, 96, 10477-10482.

Wylie, L.M. \& Gentle, M.J. (1998). Feeding-induced tonic pain suppression in the chicken: Reversal by naloxone. Physiology \& Behavior 64, 27-30.

Williams, A. C. D. C. (2002). Facial expression of pain: an evolutionary account. Behavioral and Brain Sciences 25(4), 439-455.

Wright-Williams, S. L., Courade, J. P., Richardson, C. A., Roughan, J. V. \& Flecknell, P. A. (2007). Effects of vasectomy surgery and meloxicam treatment on faecal corticosterone levels and behaviour in two strains of laboratory mouse. Pain 130(1), $108-118$.

Yoshida, M. \& Hirano, R. (2010). Effects of local anesthesia of the cerebellum on classical fear conditioning in goldfish Behavioral and Brain Functions 6, 20.

Zimmerman, M. (1986). Physiological mechanisms of pain and its treatment. Klinische Anäesthesiologie Intensivtherapie 32, 1-19. 